\title{
Environmental management of riparian tree health in the Murray-Darling Basin, Australia
}

\author{
T. Doody \& I. Overton \\ CSIRO Water for a Healthy Country, South Australia, Australia
}

\begin{abstract}
Native riparian floodplain vegetation communities within the Murray-Darling Basin have been suffering severe health decline for many years in response to decreased water availability primarily due to drought and salinity and because the forests have been receiving less flooding and less frequently. It is estimated that over $60 \%$ of riparian tree vegetation in major wetlands and floodplains is in poor health or dead. The native vegetation, predominately Eucalyptus open forest and woodlands, is dependent upon a combination of surface flooding and groundwater availability as sources of water use. Management options to improve tree health are vital to the floodplain and its wetland systems and include the application of environmental water to priority areas experiencing severe health decline. Current techniques to identify critically stressed vegetation rely on visual canopy health assessment, but it is unclear how reliable such visual indicators predict the response of trees to water application or how resilient the vegetation will be to continuing water stress. A simple, new, quantitative, field-based method has been developed to improve the identification of water stress of River Red Gums on floodplains. The method is based on the ratio of stem sapwood cross-sectional area to stem basal area (the sapwood area ratio). Research presented in this paper indicates that a dead or dying tree may or may not possess live sapwood. Where tree health has only recently declined, visual indicators of health may not detect the presence of live sapwood and therefore will underestimate the potential for the tree to recover after watering. Along with varied responses to watering, trees have also been found to suffer decline in health following the first watering. Understanding the role of the sapwood area ratio in tree response and resilience will provide better management guidelines for environmental watering. This technique therefore, provides a new tool to assist with environmental management of floodplain vegetation within the Murray-Darling Basin and other locations where trees are suffering from water stress.
\end{abstract}

Keywords: river red gum, eucalyptus camaldulensis, riparian vegetation, sapwood area, basal area, vegetation health, resilience, drought, salinity. 


\section{Introduction}

The native vegetation along the lower River Murray Floodplain in south-eastern Australia has been in decline for several decades (Jolly et al. [1]). This decline is due to the introduction of river regulation (locks, dams and weirs), long term drought and abstraction for irrigation and domestic purposes, causing a reduction in flooding frequency and an increase in soil salinisation (Overton et al. [2]). Naturally saline groundwater levels have become elevated as a result of water ponding at locks, as well as from irrigation. Salinisation of the floodplain soils has increased due to elevated water tables and evapotranspiration that has caused salt to accumulate in the upper layers of the soil (Jolly et al. [1], Overton et al. [2]). Under natural conditions, the soil would be leached by flooding, however reduced flooding frequency and below average rainfall currently prevent this. The prolonged drought has also added additional water stress to trees already in decline. As a result of changes to water availability and salinity, the dominant floodplain tree species of River Red Gum (Eucalyptus camaldulensis), Black Box (E. largiflorens) and River Cooba (Acacia stenophylla) are experiencing severe stress, leading to extensive tree deaths. It is estimated that over $60 \%$ of riparian tree vegetation in wetlands and floodplains within the Murray-Darling Basin are in poor health or dead (Cunningham et al. [3]).

Management options to improve tree health are vital to the floodplain and its wetland systems and generally include the application of environmental water to those priority areas in severe decline. Such water application has occurred at the Chowilla Floodplain and other locations in the past and research results indicate that approximately $60 \%$ of the floodplain vegetation responds positively (Watts and Herbert [4]), as determined by the production of epicormic leaf growth and increase in canopy area. However, until now there have been no methods available other than by visual health assessment, that might indicate how resilient the floodplain trees may be to further water stress, nor what proportion of the floodplain might respond to watering. A technique relating to River Red Gum tree health and its relationship to stem sapwood area has recently been assessed in an effort to address these monitoring deficits.

\section{The Lower Murray-Darling and vegetation health assessment}

The Murray-Darling Basin catchment is situated in south-east Australia (Figure 1), involving five States and Territories, occupying one seventh of Australia's land area. The Basin contributes $70 \%$ of Australia's irrigated crops and pastures. The River Murray is the primary river in the Basin, extending over 2,000 kilometres with a floodplain area of over 650,000 hectares. The lower River Murray extends from the Darling River to the Murray Mouth and Lower Lakes (Figure 1). The climate in this region is semi-arid and characterised by low rainfall $(\sim 300 \mathrm{~mm}$ at Chowilla) and high rates of potential evaporation ( $2000 \mathrm{~mm}$ at Chowilla). 

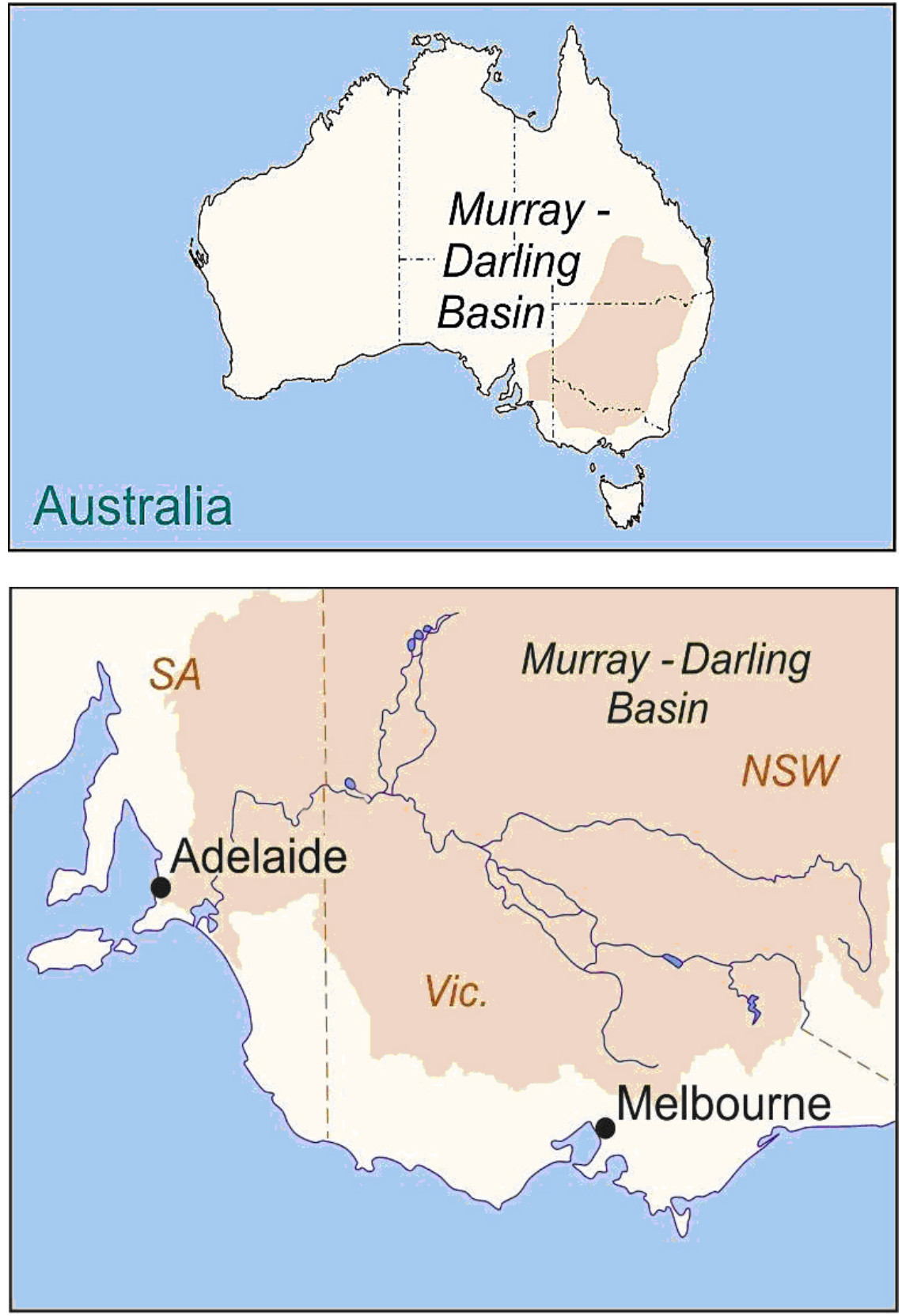

Figure 1: $\quad$ Map of the Murray-Darling Basin within Australia, showing the River Murray. 
River Red Gums, Black Box and River Cooba are the dominant tree species and their location on the floodplain is dependant on their sensitivity to drought. Red Gums are also sensitive to salinity (maximum tolerance of $~ 30,000$ EC) and prefer to be inundated every one and a half years and are therefore located in the vicinity of permanent water or along ephemeral water courses. Black Box and River Cooba are more tolerant of drought and salt stress $(\sim 55,000$ EC) preferring inundation every 3 to 5 years and are located at higher floodplain elevations.

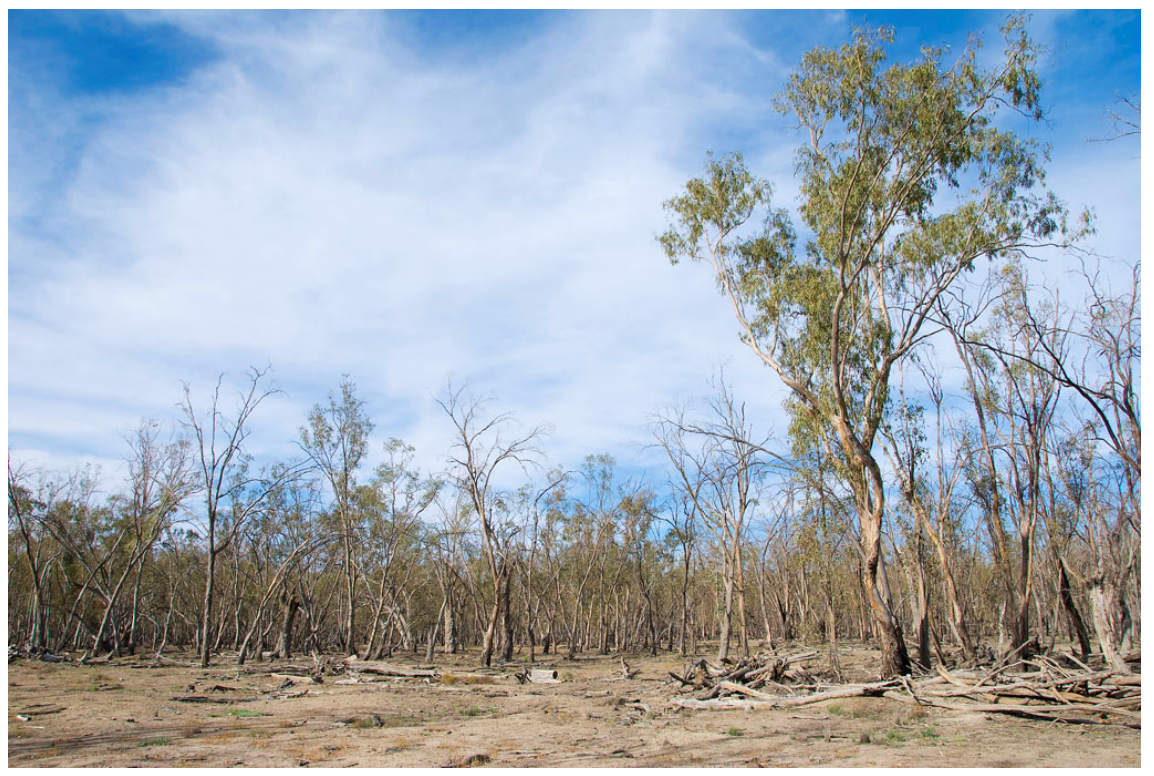

Figure 2: $\quad$ Floodplain Red Gum trees in very poor health.

Visual assessment is currently used to assess floodplain tree health, using a variety of vegetation indices such as those developed by Grimes [5], Lay and Meissner [6], Sinclair Knight Merz [7] and Tucker [8]. These methods score tree health based on criteria such as canopy biomass, presence or absence of dead branches and presence of epicormic growth. However, the visual assessments do not indicate if a tree is likely to respond to watering, applied through artificial means rather than a natural flood event, which is currently the preferred method employed to prevent further decline in tree health on selected floodplain and wetland areas of ecological importance. Visual assessments also do not provide information which might indicate how resistant a tree might be to further salt stress or drought. To address this gap in knowledge, a method has been developed that improves on current visual health assessment techniques by investigating the amount of sapwood a tree stem might possess and using this information to determine the likelihood of stressed floodplain tree recovery (in particular for River Red Gums) in response to water application and the potential resistance in relation to further drought stress. 


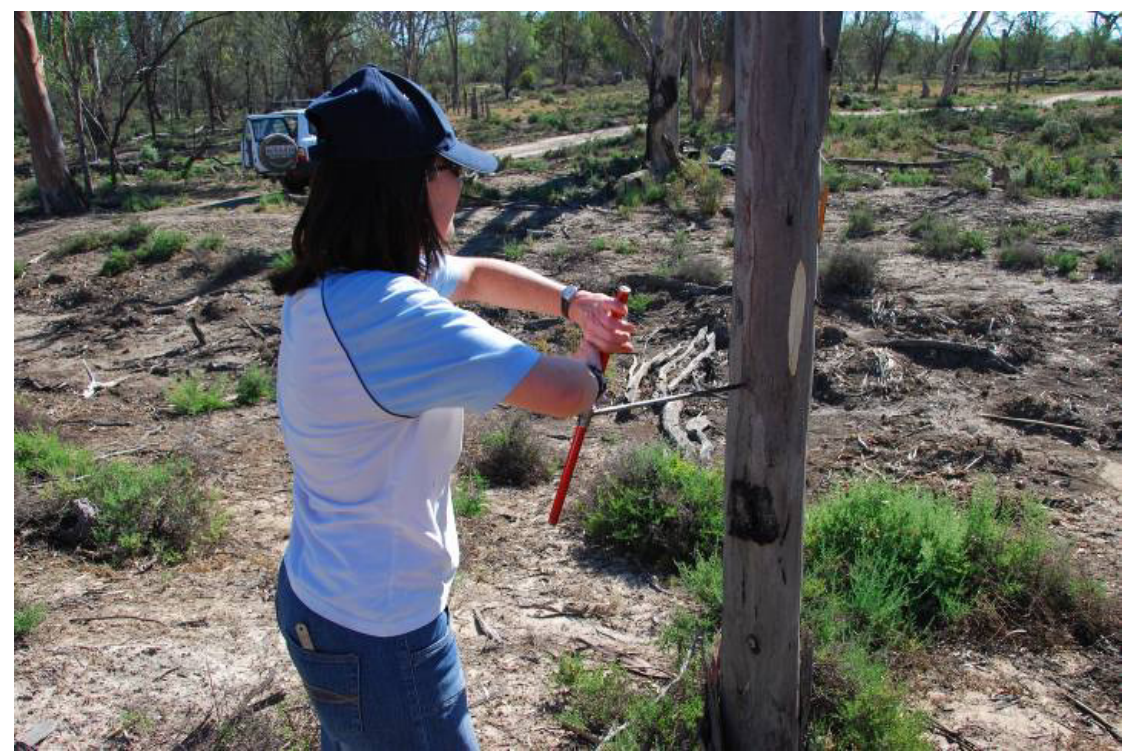

Figure 3: $\quad$ Wood corer used to extract stem core sample.

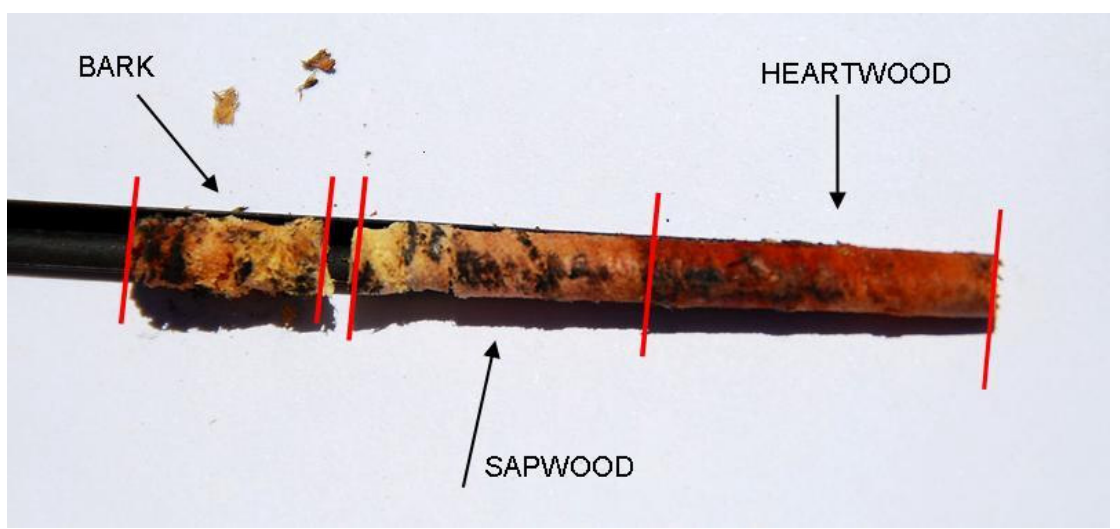

Figure 4: Tree core showing the three areas of bark, sapwood and heartwood.

\section{Sapwood area ratio}

Stem wood cores were extracted from Red Gum Trees across a range of sites in the Murray-Darling Basin and across a range of Modified Lay-Meissner Health Index (MLMHI) visual health classes (Tucker [8]) which scores trees on a scale of 0 (dead) to 5 (excellent health). Two core samples were taken at each tree using a wood corer (Figure 3) and a measure of bark thickness, at a height of $1.3 \mathrm{~m}$. In addition, the diameter at breast height $(\mathrm{DBH})$ was measured. Each 
extracted core (Figure 4) was then observed to determine the sapwood thickness. Cross-sectional sapwood area $\left(\mathrm{cm}^{2}\right)$ was then calculated for each core sample (Doody et al. [9]) and compared to the basal area over bark $\left(\mathrm{cm}^{2}\right)$ of each tree, or total stem cross-sectional area (which includes bark, sapwood and heartwood). Sapwood area ratio was calculated by dividing sapwood area by basal area (Doody et al. [9]).

\section{Results and discussion}

It was found that trees in good health (health class 5 (excellent health) -2 (health is ok)) consistently possessed a high proportion of sapwood, while trees in health classes 1 and 0 had variable proportions of sapwood. In some instances, a tree that appeared dead or in very poor health (class 0 or 1 ), had a sapwood area ratio similar to that of a health class 4 or 5 tree, indicating thick sapwood. Other trees however, with similar visual health, had a very low sapwood area ratio, indicating thin sapwood. Based on these observations, trees in health class 0 and 1 were grouped together and then separated based on their sapwood area ratios into class $0 / 1$ high sapwood area ratio and class $0 / 1$ low sapwood area ratio (Figure 5).

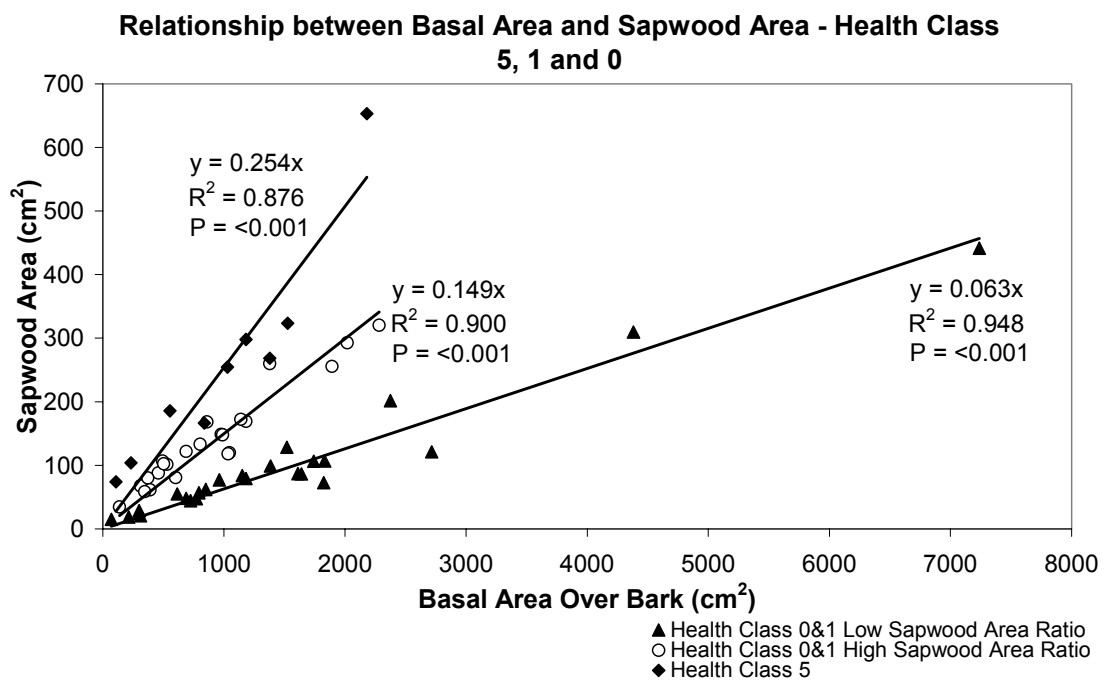

Figure 5: Relationship between sapwood area and basal area over bark for health classes 5, 1 and 0 .

It was noted by Hatton and $\mathrm{Wu}[10]$ that leaf area can decline quickly in response to drought while sapwood area of the stem remains stable. Our findings indicate that those trees in class $0 / 1$ with a low sapwood area have been enduring long-term drought stress which has lead to a decline in sapwood thickness. Trees in class $0 / 1$ with a high sapwood area, have only recently become stressed and as first response have shed their leaves. 
Class $0 / 1$ trees with a high sapwood area ratio, will therefore have greater resistance to continued stress compared with trees in class $0 / 1$ trees with a low sapwood area. Resilience, in a general sense, can be defined as the capacity of ecological communities or populations to recover from disturbance and maintain their function. As such, trees with a greater area of sapwood have a greater capacity to endure future stress but also have a much greater chance of responding positively should artificial flooding occur. The conceptual model displayed in Figure 6, highlights that trees maintaining sapwood such as class 0/1 high sapwood area ratio, potentially have a higher chance of responding to the application of water, with the primary response being epicormic leaf growth and an improvement in the visual health class of the watered trees (Doody and Overton [11]). Sapwood area is unlikely to increase in the first instance as changes to sapwood area production lag behind leaf area changes as the tree uses all available resources to produce foliage. Trees with poor sapwood health are likely to die. Thus, visual health of a canopy is not a good indicator of sapwood area ratio and of tree response to watering, especially in relation to MLMHI classes of 0 and 1 . Determination of resilience based on visual health assessment is also unreliable, as the sapwood area ratio method provides an indication that even though a tree may appear in extremely poor health or dead, it can possess a high sapwood area. Resilience of a Red Gum in poor visual health can therefore be much greater than assumed in the past.

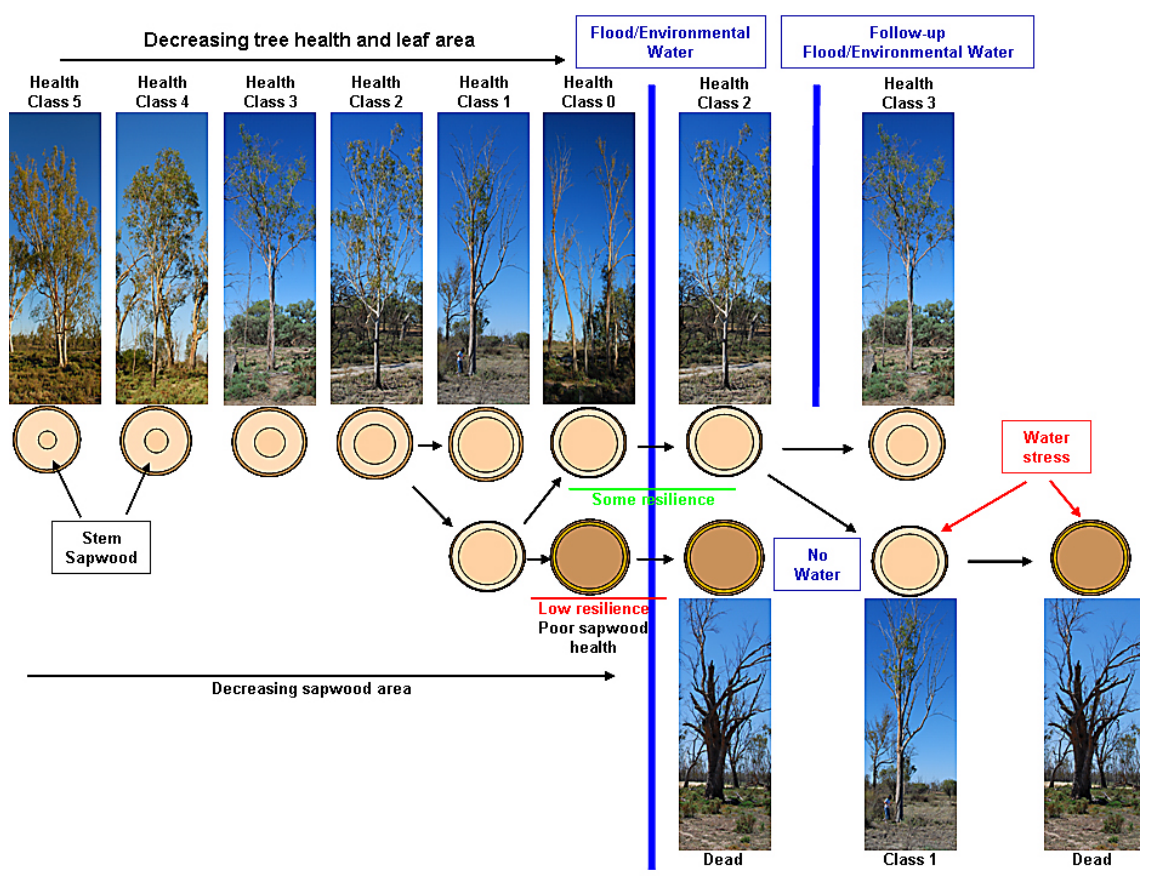

Figure 6: Conceptual diagram of tree health decline and resilience in relation to stem sapwood present. 
As indicated in Figure 6, a single watering is insufficient to maintain or restore tree health. A repeat application is required in the following winter/spring (Holland et al. [12]). Direct evidence of this has been documented recently at Bookpurnong in South Australia's Riverland. Trees lining a creek on the Murray River Floodplain received water in September, 2006, which lead to the production of epicormic leaves. Twelve months after flooding (September 2007), sample trees were in good health with low tree stress, as indicted by measurements of leaf water potential. However, 3 months later, when the average daytime temperatures was $30^{\circ} \mathrm{C}$ and with minimal rainfall, several trees were in declining health or dead, based on visual assessment of foliage, primarily as a result of water stress. Stem core samples in February 2008 confirmed the sapwood of these trees was dead. However, as illustrated in Figure 6, a second watering event would have possibly have led to a further increase in leaf area, associated with an increase in sapwood area. Further research is required to monitor the response of sapwood production in relation to watering events.

Measurement of sapwood area ratio requires a degree of technical skill and experience, therefore a simpler technique is being developed based on the existence of a strong relationship between stem diameter (DBH) and bark thickness. Trees with low sapwood area ratio also have thin bark. Both of these parameters can be quickly and accurately measured. Our study indicated that trees with a low sapwood area ratio have an average ratio of $0.023 \mathrm{~cm}$ of bark for every $1 \mathrm{~cm}$ of stem diameter. If the bark/DBH relationship is lower that tree is classified as having low sapwood area and is unlikely to respond as successfully to water application. However, further studies and analyses need to be conducted to verify this relationship.

\section{Conclusion}

Improving the health of the River Murray floodplain is a high priority of Commonwealth and State Governments in Australia. It is currently being addressed by assessment of various groundwater and surface water management options including the application of environmental water allocations to high priority areas in an effort to ameliorate decline and to protect and maintain ecologically significant floodplain and wetland flora and fauna. Currently an area designated for watering is allocated water based on its ecological significance and its health status, often determined by visual health assessment. However, the results presented herein, identify some ambiguity surrounding the application of visual canopy health assessment of those River Red Gum trees which are in particularly poor health.

A simple method presented here has the potential to provide water managers with an objective field-based technique, allowing them to rapidly determine whether a tree with poor health, as assessed visually, is more likely to respond to environmental watering. The technique will allow managers to identify floodplain tree areas in most critical need of water and to also determine the areas which will potentially receive maximum benefit from water application. 
However, further research is required to better quantify tree response to water application. Sapwood area ratio is therefore a potential indicator of drought/salinity stress in floodplain trees and may provide some indication of resilience of tree populations across a target floodplain. The method, when combined with visual canopy health assessment, may provide a powerful management tool, applicable across a broad geographic area, to assist decision making in relation to environmental watering allocations, and allowing water managers to make more informed decisions that will maximise the use of scarce water resources, improve floodplain health and maximize the ecological outcomes from allocation of environmental water in Australia.

\section{References}

[1] Jolly, I.D., Walker, G. \& Thorburn, P., Salt accumulation in semi-arid floodplain soils with implications for forest health. Journal of Hydrology, 150, 589-614, 1993.

[2] Overton, I.C., Jolly, I.D., Slavich, P., Lewis, M. \& Walker, G., Modelling vegetation health from the interaction of saline groundwater and flooding on the Chowilla floodplain, South Australia. Australian Journal of Botany 54: 207-220, 2006.

[3] Cunningham, S.C., Mac Nally, R., White, M., Read, J., Baker, P.J., Thomson, J. \& Griffoen, P., Mapping the current condition of river red gum (Eucalyptus camaldulensis Dehnh.) stands along the Victorian Murray River floodplain. A report to the Northern Victorian Catchment Management Authorities and the Department of Sustainability and Environment, 2007.

[4] Watts R, Herbert T., Rationale for watering the Chowilla Floodplain in 2007/2008. Unpublished report for the South Australian Murray Darling Basin Natural Resource Management Board, 2008.

[5] Grimes, R., Crown assessment of Natural Spotted Gum (Eucalyptus maculata) and Ironbark (E. fibrosa, E. depranophylla) forest. Queensland Department of Forestry. Technical Paper No. 7, 1987.

[6] Lay, B. \& Meissner, A., An objective method for assessing the performance of amenity plantings. Journal of the Adelaide Botanic Gardens 7, 159-166, 1985.

[7] Sinclair Knight Merz., Murray River Floodplain Salt Storage in Riparian Environments Near Mildura. Sinclair Knight Merz Report, 2005.

[8] Tucker, P., 'Your wetland monitoring manual: Data collection'. River Murray Catchment Management Board, Berri and Australian Landscape Trust, Renmark, 2004.

[9] Doody, T.M., Overton, I.C., \& Benyon, R.G., A methodology for identification of stress and resilience in floodplain trees. In Review.

[10] Hatton, T. \& Wu, H., A scaling theory to extrapolate individual tree water use to stand water use. Hydrological Processes 9, 527-540, 1995.

[11] Doody, T.M. \& Overton, I.C., Tree Health Assessment of Gol Gol Lake, Swamp and Creek; River Murray Floodplain, Mildura. CSIRO Land and Water report prepared for LMDCMA, 2008. 
206 River Basin Management V

[12] Holland K, Jolly I, McEwan K, Doody T, White M, Berens V, Souter N., The 'Bookpurnong Experiment': will groundwater management and flooding improve the health of floodplain vegetation? $2^{\text {nd }}$ International Salinity Forum, 31 March - 3 April 2008, Adelaide, 2008. 